\title{
Front Matter: Volume 11617
}

, "Front Matter: Volume 11617," Proc. SPIE 11617, International Conference on Optoelectronic and Microelectronic Technology and Application, 1161701 (4 December 2020); doi: 10.1117/12.2589811

SDIE Event: International Conference on Optoelectronic and Microelectronic Technology and Application, 2020, Nanjing, China 


\section{PRO CEEDINGS OF SPIE}

\section{Intemational Conference on Optoelectronic and Mic roelectronic Technology and Applic ation}

Yi Luo

Lianhui Wang

Yi Shi

Xiaodi Tan

Zhengyuan Xu

Editors

\section{0-22 October 2020}

Nanjing, China

\section{Organized by}

Chinese Society for Optical Engineering (CSOE)

Nanjing University of Science and Technology (China)

Nanjing University (China)

Fujian Nomal University (China)

Nanjing University of Posts and Telecommunic a tions (C hina)

J iangsu Key Laboratory of Spectral Imaging and Intelligent Sense (China)

School of Electronic Information, Hangzhou Dianzi University (C hina)

J iangsu Optic al Society (C hina)

Sponsored by

Chinese Society for Optical Engineering (CSOE)

Published by

SPIE

Volume 11617

Part One of Two Parts 
The papers in this volume were part of the technical conference cited on the cover and title page. Papers were selected and subject to review by the editors and conference program committee. Some conference presentations may not be available for publication. Additional papers and presentation recordings may be available online in the SPIE Digital Libra ry at SPIEDigita lLibrary.org.

The papers reflect the work and thoughts of the authors and are published herein as submitted. The publisher is not responsible for the validity of the information or for any outcomes resulting from reliance thereon.

Please use the following format to cite material from these proceedings:

Author(s), "Title of Paper," in Intemational Conference on Optoelectronic and Microelectronic Technology and Application, edited by Yi Luo, Lianhui Wang, Yi Shi, Xiaodi Tan, Zhengyuan Xu, Proceedings of SPIE Vol. 11617 (SPIE, Bellingham, WA, 2020) Seven-dig it Artic le CID Number.

ISSN: 0277-786X

ISSN: 1996-756X (electronic)

ISBN: 9781510640696

ISBN: 9781510640702 (electronic)

Published by

SPIE

P.O. Box 10, Belling ham, Washington 98227-0010 USA

Telephone +1 3606763290 (Pacific Time). Fax +1 3606471445

SPIE.org

Copyright (C)2020, Soc iety of Photo-Optic al Instrumentation Engineers.

Copying of material in this book for intemal or personal use, or for the intemal or personal use of specific clients, beyond the fair use provisions granted by the U.S. Copyright Law is authorized by SPIE subject to payment of copying fees. The Transactional Reporting Service base fee for this volume is $\$ 21.00$ per article (or portion thereof), which should be paid directly to the Copyright Clearance Center (CCC), 222 Rosewood Drive, Danvers, MA 01923. Payment may also be made electronically through CCC Online at copyright.com. Other copying for republication, resale, advertising or promotion, or any form of systematic or multiple reproduction of any material in this book is prohibited except with permission in writing from the publisher. The CCC fee code is 0277786 X/20/\$21.00.

Printed in the United States of Americ a by Curran Associates, Inc., under lic ense from SPIE.

Public ation of record for individual pa pers is online in the SPIE Digital Library.

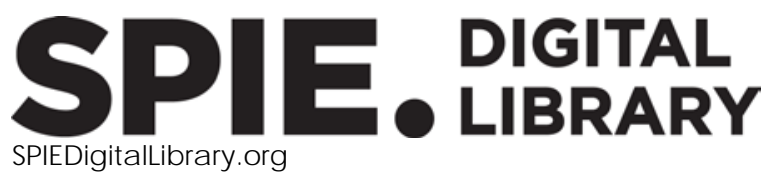

Paper Numbering: Proceedings of SPIE follow an e-First publication model. A unique citation identifier (CID) number is assigned to each article at the time of publication. Utilization of CIDs allows articles to be fully citable as soon as they are published online, and connects the same identifier to all online and print versions of the publication. SPIE uses a seven-digit CID article numbering system structured as follows:

- The first five digits correspond to the SPIE volume number.

- The last two digits indicate publication order within the volume using a Base 36 numbering system employing both numerals and letters. These two-number sets start with $00,01,02,03,04$, 05, 06, 07, 08, 09, 0A, 0B ... 0Z, followed by 10-1Z, 20-2Z, etc. The CID Number appears on each page of the manuscript. 


\section{Contents}

\section{Part One}

INTERNATIONALCONFRENCE ON OPIOELECTRONIC AND MIC ROEECTRONIC TECHNOLOGY AND APPUCATION

1161702 Gemanium/gemanium-tin heterojunc tion phototransistors: towards high-effic ient [11617-2]

1161703 Performance comparison of two OAM shift keying CNN demodulating schemes [11617-3]

1161704 Photbacoustic detection of glucose for the milk-gluc ose mixed solution [11617-4]

1161705 Intelligent reflecting surfaces-assisted petahertz mobile communication system [11617-5]

1161706 A framing method to enhance the system throughput of LD-camera based OCC system [11617-6]

1161707 A soft x-ray emission flat-field grating spectrometer for time-resolved spectroscopy [11617-8]

1161708 Quantum decoding integrated chip for quantum key distribution based on silica planar lightwave circuit technology [11617-9]

1161709 Graphene-assisted mic rowave photonics filter with flat passband [11617-10]

11617 OA Spatial beam modulator based on electrowetting liquid lens/ prism array [11617-11]

11617 OB Research progress of molybdenum disulfide field-effect transistor biosensors [11617-12]

11617 OD Hundredfold surface plasmon enhancement of fluorescence from up-conversion mic ro-nano partic les emissions [11617-15]

11617 OE Optical resonant measurement applied in magnetic field sensor [11617-16]

11617 OF Guest effect of N-butylammonium iodide for stable a-phase fomamidinium perovskite via sequential deposition method [11617-17]

11617 OG Design of circ ularly polarized folded transmitamay antenna [11617-18]

$11617 \mathrm{OH} \quad$ Fabrication of NiSs nanomaterial for $\mathbf{C a}^{2+}, \mathbf{M g}^{2+}$ sensing [11617-21]

11617 ol Quantum dot luminescence amplifier based on optical metamaterial for visible light [11617-22] 
11617 0] Study on optimal layout method of LED light source for indoor visible light communication [11617-25]

11617 OK Monochromatic Kirkpatrick-Baez microscope using two spherically bent crystals [11617-27]

$11617 \mathrm{OL} \quad$ Mic rostructure evolution during vacuum sintering of $\mathrm{Tm}, \mathrm{Ho}$ :( $\left.\mathrm{L}_{2 / 3} \mathrm{SC}_{1 / 3}\right)_{2} \mathrm{O}_{3}$ transparent ceramics [11617-28]

11617 OM Study on laser-induced damage characteristics of optical gain material [11617-30]

11617 ON Propagation of optical pin beams through waterturbulence [11617-31]

1161700 Characterization method of electric field controlled magnetism with tunneling magnetoresistive sensor [11617-32]

11617 OP Optical characteristic measurement and analysis of large-field mic ro-nano optical lenses used in UDAR [11617-36]

11617 0Q Silicon-based polarization insensitive grating coupler[11617-37]

11617 OR Study on $\boldsymbol{\beta}-\mathrm{Ga}_{2} \mathbf{O}_{3}(\mathbf{0 1 0})$ surface characteristics: a first-principle study [11617-39]

11617 OS Research on a potential electron source for BEPC [11617-40]

11617 OT Wireless ultra violet light positioning and guidance system during UAV flight [11617-43]

11617 OU Research on the positioning and assemblage algonithm of wireless ultraviolet light guiding UAVs [11617-45]

11617 OV Design of a low light level image compression circuit based on improved EAW algonithm [11617-46]

11617 OW Research progress of chlorine-free synthetic silica glass [11617-47]

11617 0X High speed data access algonithm for automatic weather station NAND flash extended storage based on STM32 [11617-48]

11617 oY Ultra-broadband generalized M/ I/M absorber for visible-near infrared band [11617-49]

$116170 Z$ Tunable electroluminescence in ionic liquid gated atomically thin p-n junction [11617-51]

1161710 Research on diagnostic system integrated nucleic acid extraction and detection [11617-52]

1161711 A brightness-enhanced and low color shift optical film with micro-prism for LCD and OLED [11617-53]

1161712 Capacity of atmosphere link with camier Bessel-Gaussian localized vortex wave [11617-54] 
1161713 HDecoder: a hardware LPPC decoder using high level synthesis for phase modulated collinear holographic storage [11617-55]

1161714 All-nomal-dispersion figure-8 and figure-9 femtosecond Yb-doped fiber lasers [11617-56]

1161715 Drawn a flexible, low-cost, eco-friendly, and multifunctional humidity sensor on paper using carbon ink [11617-59]

1161716 Cognitive cooperation optimization scheme for spectrum sharing between LEO satellite group and GEO satellite [11617-60]

1161717 Research on the cutting-edge application of high energy laser C-UAS technology [11617-61]

1161718 Detection method and evaluation of zoom CAM curve based on linear displacement [11617-63]

1161719 A novel integrated fully passive optical network for free-space optics and visible light communication for last-mile access network based on composite phosphor film [11617-65]

11617 1A Study on diffraction effic iency of Crnanograting prepared by laser-foc used atomic deposition [11617-67]

11617 1B Mophology-modeled chitosan nanoparticles/ WS2 nanosheets for advanc ing the sensing properties of triboelectric acetone sensor [11617-70]

11617 1C New insights into the controlled growth of hierarchical MoS2 nanospheres [11617-72]

11617 1D Enor rate perfomance of MIMO FSO communications for high-speed trains [11617-73]

11617 1E Preparation technology of ultra thin fused silica glass sheet [11617-74]

11617 IF Influence of mixed argon on synthesizing type IV silica glass [11617-76]

11617 1G All-dielectric nanowire waveguide with subwavelength mode confinement [11617-77]

$116171 \mathrm{H} \quad$ Ultra-long curvature radius control technology of spherical optical element during full aperture polishing [11617-78]

11617 1l Analytical solution of few-body femmionic model in synthetic gauge field [11617-79]

11617 1] Ultrathin niobium carbide nanosheets for humidity sensing [11617-80]

11617 1K A flexible piezoresistive pressure sensor with micro-papillae structure for high sensitivity and wide detection range [11617-81]

11617 1L High-Q microresonator characterization by optical frequency domain reflectometry [11617-82]

11617 1M Calculation and venification of linear target deposition distribution [11617-83] 
11617 1N Design of electrically pumped sub-mic ron lasers on pattemed Sol substrates [11617-84]

1161710 Active frequency selective surface with tunability [11617-85]

11617 1P Application of RHEED in low vacuum environment [11617-87]

$116171 \mathrm{Q}$ Synchronization control based on phase compensation of tracking emor of wafer and reticle stage in step and scan lithographic equipment [11617-88]

11617 1R Userpairing and powerallocation scheme for NOMA-based indoor VLC systems [11617-89]

11617 1S Possibility of processing a glass plate by heating the material with an ultraviolet laser [11617-90]

$116171 T \quad$ In-line fiber-optic sensor based multi-core fiberfor simultaneous transverse pressure and temperature sensing [11617-92]

11617 IU A comprehensive framework for cross domain mission planning with multiple satellite resources [11617-93]

11617 IV Photonic time-stretch analog-to-digital conversion based on complementary parallel single-sideband modulation architecture [11617-94]

11617 1W Intelligent sensor array based on machine leaming [11617-95]

11617 1X Hydrothemal synthesis of flower-shaped NiO nanomaterials and its fault detection in XIPE power cables [11617-96]

11617 IY Ultrathin transmission-type bent crystals for XFE spectral diagnostic [11617-97]

\section{Part Two}

1161720 Research on mic rostructure of optical disc and its master disc for long-life holographic storage [11617-99]

1161721 Design of feasible $\mathrm{Si}_{-\mathrm{Si}} \mathrm{N}_{4}$ interlayer polarization beam splitter toward 3D optical interc onnect [11617-101]

1161722 Detection of $\mathrm{CO}_{2}$ concentration using a fiber-optic cantilever acoustic sensor in 2.0- $\mu$ m band [11617-102]

1161723 High performance optical $90^{\circ}$ hybrid at $2 \mu \mathrm{m}$ wavelength range based on $2 \times 4 \mathrm{MMI}$ using Si3 $\mathrm{N}_{4}$ technology [11617-103]

1161724 Enhanced reconstruction of NR-LPC codes for high capacity PHz communication [11617-104]

1161725 Research on the perceived brightness for laser projection television based on RG B diode laser [11617-105] 
1161726 Dither removing of three-dimensional OCTretinal image [11617-106]

1161727 An 1.96 kHz linewidth semic onduc tor laser with extemal dual-cavity self-injec tion struc ture of the adjustable time-delay fiber [11617-107]

1161728 Application of diffiactive structure in micro-projection light path [11617-108]

1161729 A new approach of wavefiont sensorless adaptive optics based on moment estimation [11617-109]

11617 2A Design of diffrac tive optical element for ultra-thin deep ultraviolet imaging system [11617-110]

11617 2B Comection of different spatial frequency emors of large and thin optical windows based on ion beam figuring [11617-112]

$116172 \mathrm{C} \quad \mathrm{TX}_{\mathbf{2}}(\mathrm{X}=\mathrm{Cl}, \mathrm{Br}, \mathrm{I})$ monolayerand type II heterostructures as promising effic ient solar cells [11617-113]

11617 2E Research on online monitoring system of submarine cable based on bidirectional Mach Zehnder interferometer [11617-115]

11617 2F Diffiaction optical elements with broadband and large inc ident angles [11617-117]

11617 2G Multi-field simulation of thin film filter with CW laser oblique inc idence [11617-118]

11617 2H Study of AlGaAs/ GaAs low loss semic onductor coatings for prec ision measurement [11617-119]

$1161721 \quad$ Study on the optical loss of thin-film namowband filter[11617-120]

11617 2] The convergence of mid-spatial-fiequency emor of transmitted wavefront of large-aperture spherical lens by numerical control polishing [11617-122]

11617 2K Enhanced NiO hole transport layer via graphene assisted annealing for perovskite solar cell [11617-123]

11617 2L Frame ratio control algonithm for improving display accuracy of liquid crystal on silic on [11617-124]

11617 2M Genetic optimization of short block-length PAC codes for high capacity Płt communications [11617-125]

11617 2N Optimization of line edge roughness before and after etching with photoresist in soft x-ray interference lithography [11617-127]

1161720 A 32×32 SPAD anay based readout integrated circ uit for LDAR applications [11617-128]

11617 2P Self-traceable nano-grating frequency doubling based on polarization gradient light field [11617-130] 
$116172 \mathrm{Q}$ The effects of themocompression bonding on $\mathrm{Si} / \mathrm{SiO}_{2}$ multilayer thin-film based critical dimension structures [11617-131]

$116172 \mathrm{R}$ Effect of mixed spacer cation on the performance of quasi-2D blue perovskite light-emitting diodes [11617-132]

$116172 \mathrm{~S}$ On-chip high-order mode converter and a 10-channel simultaneous polarization- and modedivision-multiplexer [11617-133]

$116172 \mathrm{~T}$ Demonstration of polarization-independent broadband multilayer gratings [11617-134]

$116172 \mathrm{U}$ CNN-assisted inverse design of wavelength demultiplexer with digital metamaterials [11617-137]

$116172 \mathrm{~V}$ Design and optimization of a novel resonant gauge pressure sensor [11617-138]

$116172 \mathrm{~W}$ Wavefront measurement of membrane diffractive lens using line structured light deflectometry [11617-139]

$116172 \mathrm{X}$ Method for fabricating small space period phase elements based on magnetorheological polishing [11617-140]

$116172 Y \quad$ Research on intelligent network control mechanism and protocol verification of spatial information network [11617-142]

$116172 Z$ Structured illumination mic roscopy under low modulation-depth based on U-net leaming [11617-143]

1161730 Self-propagating welding of sapphire and Kovar by NiAl nano multilayers [11617-144]

1161731 Back-illuminated modified uni-traveling-camier photo-diodes (MUTC-PDs) with 3-dB bandwidth over 40 GHz [11617-145]

1161732 Optimized fabrication and detection of nanomechanical resonators based on graphene membranes [11617-146]

1161733 The characteristics of the channel-cut crystal modulating collimated synchrotron radiation beam [11617-148]

1161734 Complementary linearly chiped mic rowave waveform pair generation based on a Fourier domain mode locking optoelectronic oscillator[11617-149]

1161735 The control technical research of the subsecond accuracy parallelism in polishing sapphire window [11617-150]

1161736 A new method to calibrate an atomic force microscope with the self-traceable chromium grating fabricated by atomic lithography [11617-151]

1161737 Design and fabrication of diamond-based coherent x-ray compound refractive lens [11617-152] 
1161738 Research on wavefront metrology of continuous phase plate with large gradient based on phase retrieval [11617-154]

1161739 Enor analysis and comection method of axial multi-intensity phase retrieval imaging [11617-155]

11617 3A Compact portable 795nm DFB diode laser system for atom interferometer [11617-156]

11617 3B Chromatic dispersion monitoning for coherent optical communications using artificial neural network [11617-157]

11617 3C Transceiver design for two-user SIMO FSO communic ation systems over lognomal channels [11617-158]

11617 3D An optimal piecewise Chebyshev fitting method to calibrate cryogenic temperature sensors [11617-160]

11617 3E Research on accelerated storage life test for laser detectors [11617-161]

11617 3F Research on PG wavelength demodulation system based on tilted fiber grating [11617-163]

11617 3G A design with high spectral effic iency and high laser induced damage threshold for 1064nm partially reflec tive coatings [11617-164]

$116173 \mathrm{H} \quad$ Improved performance of spin-coating processed $\mathrm{Cu}_{2} Z n \mathrm{ZnS}_{4}$ solar cells using a temporary Ge layer [11617-165]

$116173 \mathrm{l} \quad$ Study on the silica immersed grating for the short-wave infrared [11617-166]

11617 3] Piezoelectric ceramics control model based on neural network [11617-167]

11617 3K Optically assisted FM demodulation of a graphene resonator [11617-169]

11617 3L Optical force induced squeezing effect in a graphene resonator [11617-170]

11617 3M A compact and robust magneto-optical trap for atom interferometry based on free space optical bench technology [11617-171]

11617 3N Perfect anomalous reflection with a multi-layer metasurface [11617-172]

1161730 Low complexity detection algonithm for multi-LDD phase-shifted space-time codes [11617-173]

11617 3P Hafnia/silica nanolaminate-based design for high perfomance laser films with low optical loss [11617-174]

11617 3Q Bended optical fiber salinity sensor with reduced temperature sensitivity [11617-175]

11617 3R Spectral beam combination of laser diode with fiber coupled output [11617-177] 
1161735 A new method for calculating the precise electrical characteristics of quantum dot mic ro-LED [11617-178]

11617 3T Design of a high-resolution compact optical system applied to mic ro-nano satellites [11617-179]

$116173 \mathrm{U} \quad$ Spatial channel model for undenwater wireless optical communication links [11617-180]

$116173 \mathrm{~V} \quad \mathrm{Ce}$ doped $\mathrm{In}_{2} \mathrm{O}_{3}$ sensors for nitrogen dioxide with reduced cross-sensitivity to oxygen at low operation temperatures [11617-181]

11617 3W Channel estimation for OFDM-based undenwater wireless optical communication systems [11617-182]

$116173 \mathrm{X} \quad$ 500Mb/s CAP256-based visible light transmission with a polynomial activation neural networkbased nonlinear equalizer [11617-183]

11617 3Y Chromatic ity-domain index modulation for visible light communication [11617-185]

$116173 Z$ Optically tuned SPR sensor [11617-186]

1161740 Technical challenge and solution for vehic le-mounted AR-HUD mass commercial application [11617-187]

1161741 Comparative analysis of measurement standards among laboratories for combustible gas detection alams [11617-188]

1161742 A fast super-resolution holographic imaging system based on compressive sensing [11617-192] 